\title{
Employees' policy implementation compliance scale (epic) on quality assurance policy in institutions of higher education
}

\begin{abstract}
Introduction: Quality assurance policy implementation is majorly done by teaching staff in institutions of higher Education. This policy has been implemented since 2006 in East Africa and there's no so far research done to evaluate staff participation in implementing the policy hence a need to develop the scale to test policy compliance. The knowledge of policy formulation appears to be a prerequisite for policy implementation.

Methods: The three major phases of developing psychological scale were followed to develop EPIC; Phase one pool items identification, phase two rigorous testing for validity and reliability which led to reduction and maintaining 16 items out of 33 pool items identified by expert panel in phase I and Phase III test -retesting and using the scale to measure what it is purported to measure. Applying the scale in intended community for further refinery to confirm its usefulness and presenting the scale to the public as to fit the purpose was done by the researcher.

Results: At factor loading; four major constructs were retained to measure policy compliance; knowledge, negotiation, empowerment and perceived service delivery. Considering accumulative percentage of principal component analysis, knowledge (cognitive value) 0.883 , negotiation between policy makers and policy implementers or involved parties 0.947 , empowerment of policy implementers in decision-making 0.873 and perceived service delivery or self-examination by service providers 0.835 . Some of the sub-constructs scored low and still retained due to their significance basing on existing literature on quality assurance policy.
\end{abstract}

Keywords: scale development, policy implementation and policy compliance
Volume 2 Issue $6-2018$

\author{
Moses Muhindo Kibalirwandi,' Akena DH, ${ }^{2}$ \\ Adrian Rwekaza Mwesigye' \\ 'Mbarara University of Science and Technology, Uganda \\ ${ }^{2}$ Psychiatrists \& Lecturer, Department of Psychiatry Makerere \\ University, Uganda
}

Correspondence: Moses Muhindo Kibalirwandi, Mbarara University of Science and Technology, Uganda,

Email kibalmoses@gmail.com

Received: August 07, 2018| Published: December 27, 2018

\section{Introduction}

Development of standardized research instruments for data collection remains a challenge for students and upcoming researchers. Employees' policy implementation compliance scale has been developed as a guiding document for collecting data on quality assurance implementation and introducing steps of scale development for research data collection. The anticipated outcome was to establish the level of policy compliance and the same tool may be used in evaluating employees' policy compliance and policy implementation in institutions with simple alterations. The scale tests compliance based on formulation cycle which is a continuous process for policy implementation to succeed. Existing literature show that scale development sometimes may affect the expected results outcome from the field. The reasons for failure to implement policies include among others domestic political realities, mismatches between the pattern of costs and benefits overtime or limited technical expertise or institutional capacity. ${ }^{1}$ In addition, some stakeholders or policy implementers are never involved during policy formulation, thus policy knowledge gaps affects the implementation process. ${ }^{2}$ Factors to be considered for knowledge are goals of institutions, purpose of the policies, mission of organization, procedures of policy formulation, clear practices and guidelines. Participation or involvement of employees in decision-making has got two major purposes; to increase employees' motivation and commitment. The employees' knowledge and skills are channeled to increase productivity and efficiency in the organization or industry. ${ }^{3}$

Each institution of higher education is expected to develop quality assurance policy which should be publically available for purpose of acquaintance. ${ }^{4}$ Unfortunately some institutions of universities have established quality assurance offices without formulating overall institutional policy or individual faculty on quality assurance which should be publically available to employees and students. ${ }^{5}$ Policy formulation has to include all stakeholders' thoughts since implementation is beneficial when taken at higher strategic level in the organization. A well formulated policy provides clear means of implementation and its benefits are seen evident at community level. ${ }^{6}$ The evidence based accountability popularizes institutional quality management hence continuous quality improvement. EPIC Scale has been developed to measure employees' policy implementation compliance in universities of Uganda. Quality assurance policy was adopted with assumption that each member state in East Africa Community where Inter University Council of East Africa (IUCEA) operates with mandate to implement international Quality Assurance Policy aiming at continuous improvement of university education globally will be effective. National council for Higher Education (NCHE) in Uganda is providing technical assistance to help universities in this country to provide quality tertiary education and implement quality assurance policy through establishing institutional 
quality assurance system. Establishing quality assurance policies aid a culture of continuous quality improvement as employees take part in policy formulation and implementation. ${ }^{4,7}$

\section{EPIC- | 6 item scale}

Employees face a number of challenges in policy compliance where knowledge gaps existence about policy formulation and implementation procedure. ${ }^{2}$ The more positive attitudes are perceived about policy implementation the more likely employees' compliance will be observed. ${ }^{8}$ Perception influences attitude change hence new behaviour development resulting from perceived knowledge., ${ }^{9}$ Measurement of policy compliance can depend on constructs like knowledge level or understanding the policy, negotiation among parties involved in decision-making, empowerment of actors or implementers and compliance can be observed through perceived service delivery to the clients. ${ }^{11,12}$ The EPIC scale was developed underscoring the four major constructs; knowledge level of the policy, negotiation on employees' involvement, empowerment in decision making and perceived service delivery. ${ }^{13}$ These major constructs had latent constructs or sub-constructs that made the 16 items in section $\mathrm{B}$ of the scale. Involvement and participation are used synonymously to explain employees' active engagement in performing duty that promotes productivity within a firm. Employees' involvement in decision making is evidence of management recognizing employees' ability to perform and increase returns to the firm. Employees participation is the most important factor of success in modern companies and organizations. ${ }^{11}$ Employees' empowerment is yet another construct which shows that employees are more engaged in running business. Employees and management recognize that many obstacles can be avoided by jointly serving clients with quality products and service. ${ }^{11,12}$ The scales of Booker and Kitchen developed in 2006 and 2010 investigated "Employees Intentions to Comply with policy" and Kielstra investigates policy implementation in companies. ${ }^{8,12}$ The Booker \& Kitchen scale investigated the intention of employees' compliance on security policy in industry type of organization in United States while Kielstra investigated using online survey challenges of companies' efficient policy implementation. ${ }^{11}$ Booker \& Kitchen scale was capturing individual's intentions to comply with security policy during their employment period. EPIC scale in this study targeted employees' compliance to policy implementation at institutional level to cause education or community reform in improving quality of service..$^{13}$

The question of how effective the policy was investigated in this study as participants or respondents attempted item 4 in section B and section $\mathrm{C}$ of the tool authenticated their personal view on the policy implementation item iii as it requires employees to identify values added in institution due to introduction of quality assurance policy. ${ }^{13}$ Quality Assurance policy is both a system and a product. ${ }^{7,14}$ Internal and external Quality assurance evaluation reports provide a platform for improvement as they are reviewed by the teaching staff and administration. ${ }^{5}$ The challenge of staff (employees') complaints that they do not understand university policy formulation procedure is a bottleneck in the implementation process. ${ }^{11}$ It is further argued that weak policy formulation procedures are manifested in poor policy implementation at a later stage which is widespread and damaging to a large majority of companies in the world today. ${ }^{11}$ Therefore competiveness is impossible in university management on the African continent. ${ }^{8,12}$ Competiveness is needed in agenda 2063 for African Human and Social capital development where it is emphasized to have quality university education for a better Africa future. ${ }^{15,16}$ The first aspiration, goal number two and priority number 1 (one) which states that, "Education and Skill Technology and Innovation" may not be achieved without research. ${ }^{16,17}$

After administering the questionnaire, item 7 in section $\mathrm{A}$, item $2 \& 3$ in section $\mathrm{B}$ and item $\mathrm{i}$, in section $\mathrm{C}$ revealed that employees' knowledge of policy formulation was a hindering factor for implementation. However, such a challenge has been identified to be a global problem in most organizations both private and public. ${ }^{12}$ The knowledge gap was identified by $81.1 \%$ participants where employees do not access the institutional policy handbooks. However, this was not wholesomely because some universities like Mbarara University of Science and Technology have some of the quality assurance handbooks volume 1, 2, 3 and 4 on the university website. The workload being reported by some participants to be too much as Comparing Enabling Efficient Policy Implementation Kielstra ${ }^{12}$ with EPIC scale, Kielstra ${ }^{12}$ was considering the means of efficient policy implementation in private and public companies while EPIC scale is targeting quality assurance policy implementation compliance in institutions. Education institutions are expected to provide continuous improved quality services to the community. ${ }^{24}$ The scale of Kielstra looks mostly on administration of policy makers who in this case are top management officers in organization both private and public. Respondents were pinning down top management and the process of policy implementation in organizations all over the world. The EPIC scale directly consider users of the policy in implementation process who at a large extend are lecturers (teaching staff) and some of the top administrators who are actively teaching despite management positions in the universities. The EPIC scale is used to test policy compliance of individuals who directly benefit from its implementation as proposed at international, national and institutional levels. The methodology used during data collection differ because the two scales (PRES by Klima ${ }^{13}$ \& OPTION by Elwyn et al.,. ${ }^{23}$ ) used online interviews where respondents did not see the researcher or research assistants hence most of the respondents ideally declined from the study without completing the survey. ${ }^{12,18,21,23}$ The EPIC scale has both quantitative and qualitative sections and can be administered directly using hard copies or electronic online approach. The researchers used informed consent during recruitment of participants who were direct beneficiaries of the policy and implementers. ${ }^{8}$ The EPIC scale was further supported by section $\mathrm{C}$ which allowed individual participants to write down their opinion that provided support evidence for policy implementation. ${ }^{8,21}$ Policy compliance is a major outcome for this study basing on the four major constructs; knowledge level or cognitive level, negotiation on involvement, empowerment in decision-making and perceived service delivery as a holistic indicator for policy compliance since policy aims at quality service delivery.

\section{Statement of the problem}

Despite the enactment of quality assurance policy by different governments, implementation in universities and other tertiary institutions is still meeting resistance from some stakeholders such as top administrators, lecturers and students. The existing literature has not provided adequate information on level of staff participation in quality assurance policy implementation in institutions of higher education. The second gap exist in failure to provide adequate guiding principles on how to develop research instruments for data collection which has remained a challenge for students and research supervisors. This document presents the three major phases explaining how the 
psychological scale (standardized questionnaire) was developed for the purpose of evaluating staff participation in quality assurance implementation in universities and providing example on how to formulate research questionnaires. This scale developed therein tests policy formulation and implementation process where the expected outcome is policy compliance.

\section{Methods}

The EPIC scale development took three phases; pool items identification, pool items developed into sentences, and pool items tested-retested to be used for the survey. Hinkin also gives the guidelines on how to develop measurement scales for survey. ${ }^{18,19}$ Option (Observation patients' involvement) scale for shared decision making between clinicians and patients was developed taking similarly procedures as what PRES (Pregnant-related empowerment) and EPIC (Employees policy implementation compliance) scale has taken. ${ }^{8,18,20}$ Finally, this EPIC scale was tested to evaluate its psychometric qualities, validity and reliability. Reliability of the scale was 0.737 cronbach's alpha and validity observed during scale development was $98 \%$. On confirmation of content validity index of complete tool, the researchers used five raters in the testing for Content Validity Index (CVI) and raters' percentages were $(100+88+$ $96+96+92$ ) while the 16 items in section $\mathrm{B}$ gave $100 \%$ alone and because raters were considering both background information items and qualitative question in section $\mathrm{C}$ then overall CVI was got to be 0.944 which stands at $94.4 \%$. Two raters are still recommended to satisfy the validity of an instrument as Neem-Abooki used two raters and while studying Total quality Management. ${ }^{15}$ It is accepted that if reliability is above 0.7 then such a scale has good test-retest reliability. ${ }^{14,15}$ However, four raters or five can be most appropriate for upcoming researchers as they develop their research tools Table $1-4$.

Table I One way analysis of variables; knowledge of policy as understood by employees in the university

\begin{tabular}{|c|c|c|c|c|c|c|}
\hline & & Sum of Squares & df & Mean Square & $\mathbf{F}$ & Sig. \\
\hline \multirow[t]{3}{*}{ Institution mission and purpose makes me enjoy my participation } & Between Groups & 0.27 & 4 & 0.067 & 0.069 & 0.991 \\
\hline & Within Groups & 36.016 & 37 & 0.973 & & \\
\hline & Total & 36.286 & 41 & & & \\
\hline \multirow[t]{3}{*}{ policy formulation procedure is clear to employees in this University } & Between Groups & 10.824 & 4 & 2.706 & 2.339 & 0.073 \\
\hline & Within Groups & 42.795 & 37 & 1.157 & & \\
\hline & Total & 53.619 & 41 & & & \\
\hline \multirow[t]{3}{*}{ Employees participate in policy formulation in this University } & Between Groups & 15.007 & 4 & 3.752 & 2.638 & 0.049 \\
\hline & Within Groups & 52.612 & 37 & 1.421 & & \\
\hline & Total & 67.619 & $4 I$ & & & \\
\hline
\end{tabular}

Table 2 One way analysis of variance Negotiation between employees and employer to allow participation

\begin{tabular}{|c|c|c|c|c|c|c|}
\hline & & Sum of Squares & df & Mean Square & $\mathbf{F}$ & Sig. \\
\hline \multirow[t]{3}{*}{$\begin{array}{l}\text { Working environment has improved, staff can execute their } \\
\text { duties }\end{array}$} & Between Groups & $1.14 \mathrm{I}$ & 4 & 0.285 & 0.25 & 0.908 \\
\hline & Within Groups & 42.192 & 37 & 1.14 & & \\
\hline & Total & 43.333 & 41 & & & \\
\hline \multirow[t]{3}{*}{$\begin{array}{l}\text { Staff involvement in decision making at all levels is highly } \\
\text { encouraged }\end{array}$} & Between Groups & 2.307 & 4 & 0.577 & 0.513 & 0.727 \\
\hline & Within Groups & 41.598 & 37 & 1.124 & & \\
\hline & Total & 43.905 & 41 & & & \\
\hline \multirow[t]{2}{*}{ Employee recognition by Management is highly satisfying } & Between Groups & $\mid 1.51 \mathrm{I}$ & 4 & 2.878 & 2.032 & 0.11 \\
\hline & Within Groups & 52.394 & 37 & 1.416 & & \\
\hline \multirow[t]{3}{*}{ promotion in professional ranks is well articulated in HR manual } & Between Groups & 7.777 & 4 & 1.944 & 1.215 & 0.321 \\
\hline & Within Groups & 59.199 & 37 & 1.6 & & \\
\hline & Total & 66.976 & 41 & & & \\
\hline \multirow[t]{3}{*}{ This institution ensures job security for employees } & Between Groups & 10.138 & 4 & 2.534 & 1.567 & 0.204 \\
\hline & Within Groups & 59.862 & 37 & 1.618 & & \\
\hline & Total & 70 & 41 & & & \\
\hline
\end{tabular}


Table 3 Empowerment of employees in decision making so as to implement policies

\begin{tabular}{|c|c|c|c|c|c|c|}
\hline & & Sum of Squares & df & Mean Square & $\mathbf{F}$ & Sig. \\
\hline \multirow[t]{3}{*}{ Delegation has improved and leadership team is observed within } & Between Groups & 4.369 & 4 & 1.092 & $\mathrm{I} .024$ & 0.408 \\
\hline & Within Groups & 39.465 & 37 & 1.067 & & \\
\hline & Total & 43.833 & $4 I$ & & & \\
\hline \multirow[t]{3}{*}{ At Department, faculty and Institution level team spirit exist } & Between Groups & 10.56 & 4 & 2.64 & 2.242 & 0.083 \\
\hline & Within Groups & 43.559 & 37 & 1.177 & & \\
\hline & Total & 54.119 & 41 & & & \\
\hline \multirow[t]{2}{*}{$\begin{array}{l}\text { There is clear recruitment procedure for employees in this } \\
\text { university }\end{array}$} & Between Groups & 3.668 & 4 & 0.917 & 0.626 & 0.647 \\
\hline & Total & 57.905 & 41 & & & \\
\hline
\end{tabular}

Table 4 Perceived service delivery by implementers of the policy to the clients

\begin{tabular}{|c|c|c|c|c|c|c|}
\hline & & Sum of Squares & df & Mean Square & $\mathbf{F}$ & Sig. \\
\hline \multirow[t]{3}{*}{ Feedback is given on quality assurance and other related policies } & Between Groups & 3.277 & 4 & 0.819 & 0.662 & 0.622 \\
\hline & Within Groups & 45.794 & 37 & 1.238 & & \\
\hline & Total & 49.071 & 41 & & & \\
\hline \multirow[t]{3}{*}{$\begin{array}{l}\text { Access to new technology is embraced and financed by this } \\
\text { institution }\end{array}$} & Between Groups & 5.217 & 4 & 1.304 & 0.86 & 0.497 \\
\hline & Within Groups & 56.117 & 37 & 1.517 & & \\
\hline & Total & 61.333 & 41 & & & \\
\hline \multirow[t]{3}{*}{ Staff morale in executing duty for productive work is high } & Between Groups & 4.243 & 4 & $1.06 \mathrm{I}$ & 0.997 & 0.422 \\
\hline & Within Groups & 39.376 & 37 & 1.064 & & \\
\hline & Total & 43.619 & 41 & & & \\
\hline \multirow[t]{3}{*}{ The progress on my duty is satisfying in this institution } & Between Groups & 4.742 & 4 & 1.185 & 0.829 & 0.515 \\
\hline & Within Groups & 52.901 & 37 & 1.43 & & \\
\hline & Total & 57.643 & 41 & & & \\
\hline \multirow[t]{2}{*}{ Employees use creative problem solving in handling clients problems } & Between Groups & 4.611 & 4 & 1.153 & 0.787 & 0.542 \\
\hline & Within Groups & 51.289 & 35 & 1.465 & & \\
\hline
\end{tabular}

\section{Phase I: Pool items identification by expert panel}

After chapter one and two of protocol \# 160104 approved by MUST-REC, the researcher consulted experts who were lecturers (practioners of quality assurance policy) at Kasese branch (satellite center) of Bugema University. These suggested pool items that rose to 33 items covering the four objectives, 13 items in the background information of respondents and three qualitative questions to capture in-depth opinion of respondents. The tool was subjected to rigorous screening and major constructs were identified. The underlying constructs were also identified and retested to generate the 16-item scale in phase II.

\section{Phase II pool item development}

The total of twenty seven research items having seven as background items, sixteen items as major sub-constructs in section
$\mathrm{B}$ and four qualitative items having open-ended questions were administered on as in the pilot study.

\section{Phase III pool item pre-test and testing for survey}

The pool items were pre-tested and retested using different participants enrolled from research communities of Mbarara University of Science and Technology and Bugema University whereby the two universities provided appropriate sample to represent the targeted six universities. The six universities included in the final data collection where this tools is to be used represents 21 universities in Uganda that were in existence ten years ago before the onset of this study. Participants' enrollment for the study depended on employment experience of more than 3 years service in the university.

The researcher used the developed scale to test for policy compliance during evaluation of staff participation in quality assurance 
implementation in universities in Uganda. The tested scale maintained seven items in section A (Background information for participants), 16 items in section B (testing policy compliance) and four openended questions in section $\mathrm{C}$ to collect participants' opinions aimed at establishing hindering factors and recommendations on how to improve policy implementation. The last item in section $\mathrm{c}$ aimed at testing staff understanding of the concept of quality assurance in universities. However, other authors detail these phases into seven steps of formulating psychological scales. ${ }^{19}$ The theoretical basis of establishing items, designing individual items and eliminating items of low repeatability process begins as shown in phase 1. In phase II assessment of reliability and validity was done, determining validity of variables. Determining convergent and divergent validity was further performed. Finally in phase III a tool was retested, put to use and finally used as a standardized scale to establish or measure what it purports to measure. These seven or more steps can be grouped into three phases as mentioned above. ${ }^{8,12,18}$ The reliability remained high; hence, consistency was seen in the scale to be used for testing policy compliance in institutions of higher learning.

\section{Results for the study}

The data was collected from three Universities where 42 participants were enrolled for the survey. The participants were lecturers of middle age between $31-50$ years constituting $81.0 \%$ and the rest of the participants were above 50 years of age. This age is a productive and stable age group that can concentrate at work once given morale and support by administrators within the university. The researcher was gender sensitive where $28.6 \%$ were females and $71.4 \%$ were males. This was observed normal since female access to education is being emphasized globally. ${ }^{9}$ The factor that adolescent school drop out for girls was previously identified to be high as $91.6 \%$, getting $28.6 \%$ female respondents in this study was incredible. The policy sensitization level was reported to be below $25 \%$ by $(21.4 \%)$ of respondents, almost $50 \%$ was acknowledged by $(26.2 \%)$ while $75 \%$ was acknowledged by $(28.6 \%)$ and $100 \%$ was acknowledge by $(11.9 \%)$ and $(11.9 \%)$ disputed that there is no policy sensitization among employees. The researchers concluded that $88.1 \%$ of the respondents acknowledge Quality assurance policy awareness in Uganda. The 16 items were analyzed to determine the strength of the relationship between variables. ${ }^{22}$ The researchers hypothesized that, "there is no significant relationship between staff participation and policy implementation in institutions of higher education". Pearson correlation between of variables tested to be 0.709 which was significant showing that a relationship exists between means of staff participation (MSTP) and means of quality assurance implementation (MQAIM). A scatter plot table was constructed showing a linear relationship between staff participation and quality assurance implementation in universities (Figure 1 in the appendix). However, there are some other factors responsible for policy compliance such as "political will", negotiation between parties based on mutual benefits that may accrue to either party in the implementation process. ${ }^{8}$

Knowledge of the policy was not clear to the participants (university staff) as it was revealed in section $\mathrm{C}$ which the researcher used to provide confirmatory evidence to the statistics analyzed in section B. The scale was measuring major constructs; knowledge, negotiation, empowerment and perception (attitudes) of participants towards policy implementation and the magnitude of policy implementation within national institution of higher Education. The expected outcome was to determine the level of policy compliance. The major study was evaluating the staff participation in policy implementation compliance which was observed from both attitudes of implementers and magnitude as observed basing on the EPIC and checklist provided in the protocol. The use of one-way ANOVA technique determines if there is a significant difference among three or more means. ${ }^{22}$ The items in section B were considered significant for EPIC basing on the level of sensitization among implementers of the QA policy. ${ }^{1}$ The difference in means signifies that if within group mean is almost equal to between group means then an item would be dropped or maintained on the scale after considering the literature and importance of item on the scale. These items were maintained because of their significance like item one with p-value 0.069 .

\section{Critical commentary for Table I}

The three sub constructs under knowledge of policy understand of institution mission, purpose, and philosophy was observed significant not because of sensitization on quality assurance policy but because each institution has got its purpose depending on the history and purpose of establishment. Item 2 and 3 on policy formulation and employees participation in policy formulation process analysis of variance appeared as difference between groups means was great than within group means yet $\mathrm{p}$-value was greater than one. This shows that participants rejected their positive meaning hence $68 \%$ of the participants disagreed, moderately agreed hence they do not accept that policy formulation process is clear to them. In the situation where between group is greater than within group means and $\mathrm{F}$ test is greater than 1 a possibility of rejecting the null hypothesis. ${ }^{24,25}$ Item 1 was accepted to be significant at 0.991 yet the difference in means was great but not due to the policy sensitization because mean square between groups was smaller than mean square within groups and $\mathrm{F}$ test was 0.069 which too was small than 1 . The cause was that each institution was having good mission, vision and purpose for its establishment on papers. The same idea or interpretation of all items that appear with high significance yet the participants are showing that quality assurance policy compliance is institutionally accepted policy but procedures or system of implementation is lacking due to knowledge gaps, negotiation between policy makers, empowerment hence employees still feel not performing well because of hindering factors mentioned in section $\mathrm{C}$ of the tool. The implication of mean square where between groups is greater than within groups and $\mathrm{F}$ test being greater than 1 , then each item would be rejected and dropped from the scale but for this study such items were maintained because of existing literature that provides how significant they are in the policy formulation and implementation. The level of staff sensitization on QA policy items 1, 4, 5, 11 and 12 accumulated less mean square between groups and $\mathrm{F}$ test value was less than 1 hence these were retained on the scale because of their significance and participants claim that sensitization on QA policy is ideally related to the institution mission, working environment and staff involvement in decision making. There is clear recruitment and feedback on policies given the similar circumstances respondents were closely homogeneous in terms of age, gender, academic qualification, professional ranks and existing salary scale. Some participants argued that salary may not be enough to motivate employees but non-wage incentives like lunch meals, house rent, loan schemes, scholarships and promotions in ranks could be better. Motivation of employees or morale is achieved through provision of non-wage incentives as mentioned by respondents in section $\mathrm{C}$ of the scale. 


\section{Critical commentary for negotiation}

Item 4 \& 5 where employees appreciate good working environment and staff involvement in decision making at departmental level, between groups means was less than within groups means and $\mathrm{F}$ test was less than one. This means that when you even check on the frequencies strongly agree and agree accounted for $61 \%$ while moderately accounted for $28 \%$. This can be approximately $75 \%$ agreed with improved working environment in universities. Items six, seven and eight on the questionnaire, F-tests for each were as 2.032, 1.215 and 1.567 respectively which is greater than one as earlier said that for P-value greater than 1 indicates that participants or situation is not as stated in the variable or questionnaire item hence the opposite of the statement is accepted. ${ }^{25}$ Critical commentary for the items $(9,10$ and 11) in the table above, delegation and team spirit situation is not friendly as expected because of quality assurance system. Employees appreciate recruitment procedure in the universities. Considering the frequency tables agree and strongly agree takes less than $50 \%$ hence working environment needs improvement so that employees feel empowered to participate in the implementation of quality teaching hence quality assurance. Critical commentary, on the above is that participants responded on items 12 where between groups means was less than within groups means and F-test was less than 1 meaning that feedback on some related policies was being given to the employees. Item 13 to 16 between groups means was greater than within group means and $\mathrm{F}$ tests were less than 1 and significance for each item was above or almost equal to 0.5 meaning relationship exist.

\section{Discussion}

This scale is measuring variables that cannot easily be measured like weight in kilogram or length in meters, using cluster variable or group variables helps in measuring what a researcher may wish to measure. For instance the researcher wanted to measure policy compliance in evaluating staff participation in quality assurance policy implementation. The pool items identified by the expert panel were 33 hence these were reduced to 16 items as in process of scale development. ${ }^{13}$ The best to handle such problem is to apply factor analysis or principle component analysis so as to get variables that can stand in to measure what a researcher's tool purports to measure. This technique helps in clustering variables that relate in measuring major constructs. The pool items that are able to explain a given construct are emerged into a sentence hence reducing items to manageable number of items in terms of space and time. Correlated variables are latent variables that are measuring or using sub-constructs that correlates hence, such would measure the same dimensions. ${ }^{25}$ For the researcher to be successful with factor analysis he/she should be able to;

a. Understand the structure of the set of variables (pool items)

b. Construct a set of questionnaire with sub-constructs that explain the original information about the research problem

c. Reduce the data set to manageable size while maintaining the original information and major constructs that outcome is realized.

The above mentioned guidelines help the questionnaire not to be big with so many items (questions) because respondents may not be willing to answer a large or many questions for research. It is upon this background that the researcher took decision to interpret situation basing on expert panel responses and pilot study participants' responses and existing literature and maintained the sixteen items in section B of the scale. The tool has got section A with biographical items and section $\mathrm{C}$ with four open ended questions so as to capture any other emerging opinions from participants. The 16 items were analyzed considering the level of employees' sensitization on quality assurance policy based on the four mentioned constructs; knowledge, negotiation, empowerment and perceived service delivery by employees. Participants who asserted that policy awareness campaigns were done in the universities were $88.1 \%$. This scenario prompted the researchers to involve in-depth interviews to establish why implementation is not as expected in these universities that were in service before 2005. This EPIC scale provides an opportunity to collect participants' opinion on policy implementation since it has three sections A, B and C. Section C had open ended items that require participant's opinion.

The participants' responses were substantial to prove that policy implementation is a continuous process for policy formulation. Policy implementation has suffered failures because of poor foundations in the formulation process as it fails to;

i. Clarify aims and goals for which a policy is to achieve

ii. Identify anticipated hindrances for policy implementation

iii. Sourcing resources to use in implementing the policy

iv. Integrating resources and inputs working in harmony to achieve organizational goals for which a policy is formulated.

v. Identifying direct and indirect benefits of employees and institution.

vi. Any policy should aim at solving community problem in order to improve livelihood. It can be strategic policy for economic improvement or strategic reform. Policies are not self-executing they must be implemented by parties that are knowledgeable and facilitated for this matter.

Therefore, the researcher after consulting expert panel members to come up with pool items took decision on what outcome is to be measured in this study. The level of staff participation and policy compliance were the end results. However, the objectives required both questionnaire and checklist which involved in-depth inquiry hence the main study used more research tools besides the epic scale which only tested for policy compliance in institutions of higher education. Appendix 03 is the said tool for this article. The factor analysis used table of communalities, factor one represented horizontal axis to measure sociability and factor two representing vertical axis as in Table 5 in the appendices. Reverse-scoring items were marked with asterisks so that the statistician may be alerted to make adjustment as he/she runs the statistics. The reverse scoring helped in establishing factor loading, and avoiding guess work among participants hence it is important for researchers to include reverse scoring items. ${ }^{8}$

Considering Table $5 \& 6$ in the appendices where factor analysis (principle component analysis) has been presented after considering latent variable as clustering of variables basing on identified constructs; knowledge, negotiation, empowerment and perceived service delivery among employees compliance to policy implementation. These variables cannot be directly measured because they are behavioural in nature. Andy Field suggests that this technique has three main uses ${ }^{24}$

a. To understand the structure of a set of variable,

b. Construct a questionnaire to measure underlying variables,

c. To reduce data set to a manageable size while maintaining the original information as much as possible."

Factor loading can be sought of as a Pearson correlation between factors and variables. ${ }^{25}$ Table 5 in the appendices shows communality is a proportion of variance among variable. And principle component work on principle that all variance is common hence Table $5 \& 6$ presents variable used in establishing policy compliance in universities. These 
five items were seen significant hence they were accepted to continue appearing among scale items because existing literature identifies item 1 as significant for institution to have mission and vision. It is within the purpose of Quality assurance policy to help institutions to improve working environment for quality services to students and staff. As the employees negotiate to be rewarded, employers ought to equip them with appropriate tools. Rewards are imperative for any computing institution of higher Education. Employees were regarded to be the first clients to each of the institutions in which the study conducted. The question of recruitment in item 11 was also pertinent according to the literature review yet during data analysis it proved that there was no significant relationship with sensitization or awareness. As this item 11 was analyzed, its' between groups mean square was 0.819 while within groups mean square was 1.238 and $\mathrm{F}$ test value was 0.621 as in Table 3 above. Finally item 12 was observed to be less significant as between group mean square was 1.185 while 1.430 within group mean square was greater and $\mathrm{f}$ test was got to be 0.787 which is less than 1 . This item was retained because feedback on policy issues is paramount in implementation process. Administratively communication gaps should be bridged so as to improve the working environment hence quality service to all stakeholders. The items mentioned to have low F test value or P-value above $\alpha$ were maintained because of their importance basing on the existing quality assurance policy literature. ${ }^{18}$ However, this tool can deeply be explained as policy compliance if correlations among items are well interpreted as these 16 items provides sufficient measurements to test policy compliance Table 7 .

\section{Recommendation}

The knowledge of scale development process is crucial for students in universities because data collection, analysis and presentation of result rely greatly on how best the tool tested what it projected to test. Sub-constructs may be added on knowledge items, negotiation, empowerment and perceived service delivery if open ended items are removed to make the study purely quantitative in nature since it is sufficient to yield results. In case items are reduced from this scale its reliability may fall making it a weak tool in testing what it purports to measure.

\section{Ethical consideration}

The study was approved by Mbarara University of Science and Technology-Research Ethics committee (MUST-REC) references MUREC $1 / 7$ and Uganda National Council of Science (UNCST) reference SS-4248 as by August 2016 and March 2017 respectively.

\section{Acknowledgment}

I thank the administration of MUST for organizing special training for employees and students in this programme. I thank all facilitators/ instructors that I have met at different conferences, workshops and seminars organized Mbarara University Research Training Initiative (MURTI). Finally, I thank all participants in this study from the six universities; Mbarara university of science and technology, Bugema University, Kyambogo University, Uganda Martyrs university, Kampala International University (Western Campus), and Nkumba University.

\section{Conflicts of interest}

No conflict of interest! This study is only for academic purpose and quality improvement in research and publication.

\section{References}

1. Hall DS, Levi M, Pizer WA, et al. Policies for Developing Countries Engagement. The Harvard Project on International Climate Agreements. $2008 ; 1-44$

2. Kibalirwandi MM. An Evaluation of Staff Participation in Quality Assurance Implementation in Institutions of Higher Education in Uganda. A protocol \# 160104 Accepted by MUST-REC: MUST. 2016.

3. Gifford J, Neathey F, Loukas G. Employee Involvement Information, Consultation and Discretion. London: Institute of Employment Studies (IES). 2005;111

4. IES. News \& commentary.

5. ENQA. Standards and Guidelines for Quality Assurance in the European Area. Helsinki. 2009.

6. HAQAA. African Standards and Guidelines for Quality Assurance in Higher Education (ASG-QA). Draft vision for Consultation May 2027. Harmonization of Africa Higher Education quality Assurance and Accreditation. 2017.

7. Hanzi S, Meschik M, Sammer G. Policy formulation and Implementation. University of Bodenkultur Vienna. 2003.

8. IUCEA. Road Map to Quality, "A hand book for quality Assurance for Higher Education” Draft copy volume 4. Guideline for self-Assessment at Institutional level. Sources IUCEA/CHE/ NCHE/TCU/DAAD. 2010;4.

9. Kibalirwandi MM. Women's Role in Reducing Adolescent Girl-Child School Dropout in Developing Countries. 2016;4(6).

10. Tibanyendera B. Head teachers leadership Behaviours as perceived by teachers in Ankole Government-Aided Secondary Schools. Department of Educational Foundational and Psychology in the Fulfilment of the Requirement for the Award of the Degree of Doctoral of Philosophy in Education of Mbarara University of Science and Technology. 2013.

11. Apostolou A. Employee Involvement. Report produced for the EC funded Project. Department of Engineering and Management. Technical University of Crete. 2000.

12. Kielstra P. Enabling Efficient Policy Implementation. Economist Intelligence Unit. 2010.

13. Shabani J, Okebukola P, Sambo A. Recognition of Studies, Providers and Quality Assurance in Higher Education: Perspective from Africa. Paris: UNESCO. Global Forum on International Quality Assurance. Accreditation and Recognition of Qualification in Higher Education. 2002.

14. Kibalirwandi MM. An Evaluation of Staff Participation in Quality Assurance Implementation in Institutions of Higher Learning in Uganda. Recommended dissertation for partial fulfilment for the award of Doctor of Philosophy of Mbarara University of Science and Technology. 2018.

15. Amin ME. Social Science, Research Conception, Methodology and Analysis. Kampala. Makerere University Press. 2005.

16. The African Union. Agenda 2063, "The Africa We Want" a shared Strategic Framework for Inclusive Growth and Sustainable Development. First Ten Years Implementation Plan 2014-2020. 2015.

17. Kibalirwandi MM \& Mwesigye AR. Pedagogy and Research at work during the era of Quality Assurance Implementation in Universities. Art human and open acc j. 2018;2(2):93-100.

18. Klima SC. Development of the Pregnancy Related Empowerment Scale. 2015.

19. Neem-Abooki. Integration of Total Quality Management in the Management of Universities in Uganda. A thesis Submitted in Partial Fulfillment of the Requirement for the Degree of doctor of Philosophy 
of Makerere University. Makerere Journal of Higher Education. 2004;1:121-134.

20. Timothy R Hinkin. A Brief Tutorial on the Development of Measures for Use in Survey Questionnaires. Organizational Research Methods. 1998;2(1):104-121.

21. Booker QE, Kitchen FL. Changes in Employee Intention to Comply with Organization Policies and Procedures Factoring Risk Perception A comparison of 2006 and 2010. Issues in information system. 2010;11(1):1-10.

22. Morse JM. Principles of Mixed Methods and Multi-method Research
Design. In: Tashakkori \& C Teddlie, Editors. Handbook of mixed methods in social science and Behavioral Research: Thousand OAKS, CA. Sage. 2003.

23. Elwyn. Sharing Decision Making: Developing the OPTION Scale for measuring Patient Involvement. Qual Saf Health Care. 2003;12(2):93-9.

24. Field A. Discovering Statistics Using SPSS. $3^{\text {rd }}$ Edition. London: Sage. 2009.

25. Bluman EG. Elementary Statistics: "Step by Step Approach". Boston: McGraw-Hill. 2004. 